EXTENDED REPORT

\title{
Globe conserving treatment of the only eye in bilateral retinoblastoma
}

\author{
V Lee, J L Hungerford, C Bunce, F Ahmed, J E Kingston, P N Plowman
}

Br J Ophthalmol 2003;87:1374-1380

See end of article for authors' affiliations

....................

Correspondence to: Mr John Hungerford, Ocular Oncology Service, St Bartholomew's and Moorfields Eye Hospitals, City Road, London ECIV 2PD, UK ;

John.Hungerford@

bartsandthelondon.nhs.uk

Accepted for publication 16 February 2002

\begin{abstract}
Aims: To quantify the rates of eye preservation and patient survival, local tumour relapse and recurrence, and development of new tumours in the remaining eye of children with bilateral retinoblastoma with one eye already enucleated. Also, in the same children, to describe the types of primary and secondary treatment procedures, and to define the anatomical outcome.

Methods: This is a retrospective observational case series report. The study participants consisted of 107 patients with bilateral retinoblastoma with one eye enucleated within 1 month of baseline examination and had their remaining eye treated conservatively. The main outcome measure were: primary treatment failures, new tumours, enucleation of the only eye, death, remission, and anatomical outcomes (retinal detachment, vitreous haemorrhage, and cataract).

Results: The median age at diagnosis was 8.4 (range 0.2-44, SD 10.1) months with a median ophthalmic follow up of $44.3(8.1-114$, SD 10.1) months. In 22 of the 107 patients (21\%) the treated eye was in Reese Ellsworth groups I or II and in the remaining $85(79 \%)$ in groups III-V at diagnosis. The primary treatment was cryotherapy in $14 \%(15 / 107)$ of eyes, radioactive plaque brachytherapy in $3.7 \%(4 / 107)$, and chemotherapy in $10 \%(11 / 107)$. It was lens sparing radiotherapy in $37 \%(40 / 107)$, whole eye radiotherapy in $29 \%(31 / 107)$, combined radiotherapy and chemotherapy in $2.8 \%$ (3/107), chemothermotherapy in $0.9 \%(1 / 107)$, and combined focal therapy in $1.8 \%(2 / 107)$. The primary treatment failed to achieve local tumour control during the follow up period in 37\% (40/107) of eyes. In 17 eyes failure was due to inadequate control of the presenting tumour, in 16 to development of a new tumour, and in eight eyes to a combination of both. $35(88 \%)$ of the 40 failures were managed by secondary conservative treatment and the remaining five were treated by enucleation of the only eye. There were eight $(7.4 \%)$ deaths and the 3 year survival rate was $93 \%$ (100/108). Anatomical results included vitreous haemorrhage in four cases, tractional retinal detachment also in four cases, and 24 children required cataract surgery.

Conclusions: Aggressive conservative treatment achieved a good rate of globe salvage without impairing survival.
\end{abstract}

$\mathrm{T}$ he primary aim of treatment in retinoblastoma is the prevention of death from metastases. The tumour is eminently curable, with an overall 3 year survival rate of between $88 \%^{1}$ and $93 \% .^{2}$ Consequently, in developed countries, the emphasis of treatment strategies is on conservative techniques designed to achieve the secondary objective of preserving vision. In the 1970s, we reported that one in five ${ }^{3}$ patients presenting with bilateral retinoblastoma suffer the eventual loss of both eyes. When a child has already lost one eye from retinoblastoma, preservation of a functional remaining eye becomes a major issue for the patient, the family, and the clinician. Difficult management decisions have to be made that strike a safe balance between, on the one hand, the potential benefits of preserving the eye with useful visual function and, on the other, the hazards of local treatment failure leading to metastatic disease. There is also a risk that excessive treatment might induce second, non-ocular cancers to which children with bilateral and therefore genetically determined retinoblastoma are particularly susceptible. ${ }^{4}$

\section{PATIENTS AND METHODS}

\section{Inclusion and exclusion criteria}

The study was a retrospective observational case series report of children treated between January 1983 and July 1997. Included in the study were all patients presenting with bilateral retinoblastoma who had one eye enucleated and globe conserving treatment of their remaining (study) eye commenced within 1 month of baseline examination. To ensure a consistent management approach, one ocular oncologist (JLH), one paediatric oncologist (JEK), and one radiotherapist (PNP) treated all the study patients. The following were excluded from the study: children who had globe conserving treatment for the tumours in both eyes for more than 1 month after baseline examinations and children who were referred to our service after retinoblastoma treatment was initiated elsewhere.

Examination, treatment, and follow up protocol

One of the authors (JLH) performed indirect ophthalmoscopy with scleral indentation under general anaesthesia on every patient at the baseline examination. All patients underwent B-scan ultrasonography of the eye to document the size and extent of the tumours and computed tomography of the brain and orbits to detect any intracranial extension. The paediatric oncologist (JEK) performed a systemic metastatic evaluation on each patient together with genetic testing for the $13 \mathrm{q}$ deletion. The decision to remove the first eye was based on one or more of the following findings: presence of tumour in the anterior segment with or without rubeotic glaucoma, extensive tumour filling more than half of the globe and/or involvement of the optic nerve. After enucleation, the patients then underwent a variety of globe conserving treatments for their remaining eye based on the extent of disease. The treatment initiated to control the tumour(s) in 
the study eye found at baseline examination was designated as the primary treatment, and any further treatment for failure to respond, relapse or recurrence of the original tumour(s), and/or for new tumours was defined as secondary treatment. Triple freeze-thaw cryotherapy was the primary treatment of choice for single or multiple pre-equatorial tumours $6 \mathrm{~mm}$ or less in diameter. In the early part of the study period indirect xenon arc photocoagulation was used as a primary treatment for small post-equatorial tumours. Radioactive plaque brachytherapy was the preferred primary treatment for single tumours more than $6 \mathrm{~mm}$ and up to $13 \mathrm{~mm}$ in diameter. Early in the study, this was administered using a cobalt-60 plaque, later with an iodine-125, and finally with a ruthenium-106/rhodium-106 applicator. This method was also used as a secondary treatment for single tumours which had remained uncontrolled with laser or cryotherapy or for tumours that had relapsed locally. An iridium-192/ platinum wire ${ }^{5}$ has been used as a secondary treatment since 1987 to treat more diffuse disease such as a vitreous base tumour recurrence. Diode laser chemothermotherapy ${ }^{6}$ (CTT) has been used since the mid-1990s to treat small tumours in Reese Ellsworth group I or II patients with tumours too posterior for plaque or cryotherapy treatment. Intravitreal thiotepa was occasionally used as a last resort treatment for vitreous seeding in an only eye with good or potentially good visual acuity where all other conventional forms of treatment had been exhausted. All the treatments described above were designated as focal treatments in this study. Before 1985 all tumours that were unsuitable for focal treatment underwent external beam whole eye radiotherapy (WERT). ${ }^{7}$ From 1985, lens sparing radiotherapy (LSRT) ${ }^{8}$ became the treatment of choice for eyes with Reese Ellsworth groups I-III disease as this method minimised the ocular surface and anterior segment complications associated with whole eye irradiation. Anterior tumours outside the lens sparing beam were treated with focal treatment (usually cryotherapy) to maximise the use of this technique. Both WERT and LSRT were used as secondary treatments over the study period for patients who had failed primary focal treatment. All external beam radiotherapy was administered in 20 or more fractions under general anaesthesia as described in our earlier publications. ${ }^{78}$ The follow up schedule post-radiotherapy included examination under anaesthesia 1 month after the completion of treatment followed by examinations at 3 monthly intervals for the first post treatment year. Patients who had focal treatment of pre-equatorial tumours and who received lens sparing radiotherapy were examined approximately half way through their radiotherapy cycle to ensure that their anterior tumours were controlled. We then performed examinations at longer intervals according to the level of tumour control in the individual patient. In the early 1990s, before the widely accepted transition from external beam radiotherapy to chemotherapy as the preferred primary treatment for tumours unsuitable for focal treatment, we treated some Reese Ellsworth group V eyes with a combination of radiotherapy and chemotherapy. ${ }^{9}$ From the mid-1990s onwards, chemotherapy (using a triple drug protocol consisting of vincristine, etoposide, and carboplatin), in conjunction with focal therapy, became the standard primary treatment for such tumours. The follow up schedule for chemotherapy patients included examination under anaesthesia after every two cycles of chemotherapy until the end of the treatment regimen, after which examinations took place at longer intervals according to the level of tumour control. Chemotherapy using the triple drug protocol was used throughout the study period as an important secondary treatment for patients failing focal treatment and external beam radiotherapy. Second line chemotherapy using other drug combinations was also used when primary chemotherapy failed to achieve tumour control or to treat new tumours. Both chemotherapy and external beam radiotherapy were designated as non-focal treatments in this study. Patients with inactive disease were followed with examinations under anaesthesia at 3 monthly intervals until the age of 1 year after which the follow up interval was increased to 4 months in years 2 and 3, and 6 months thereafter. From the age of 4 years, cooperative children were examined awake in the clinic. Patients with inert ocular tumours and no sequelae of therapy requiring ongoing treatment were discharged from the ocular oncology service by age 7 years. Owing to the ongoing risk of second tumours the follow up would be continued in the paediatric oncology service (JEK) until the age of 16 years.

\section{Data recorded}

The data abstracted from the case notes included baseline demographic variables. Baseline ocular variables included the laterality, visual acuity in the eye (if measured), intraocular pressure (if measured), presence of anterior segment tumour involvement including iris neovascularisation and tumour deposits, and posterior segment findings. Baseline tumour variables included the diagnosis type (sporadic, familial, or $13 \mathrm{q}$ deletion), the number, location, and size of individual discrete intraretinal tumours. Also recorded were the presence or absence and the extent of intravitreal and subretinal tumour seeds. Each affected eye was grouped according to the Reese Ellsworth classification (Table 1). ${ }^{10}$ Treatment variables included any focal or non-focal treatments administered as primary or secondary treatments. At follow up, the outcome variables recorded were: primary treatment failures (failure of the primary treatment to control growth of the original tumour(s) or a relapse or recurrence of the original tumour(s) after an initial favourable response), new tumours (development of new tumours not noted at baseline examination), enucleation of the study eye, death of the patient (from tumour or treatment related causes), and disease remission (study eyes with inactive tumours that did not require enucleation at the last follow up visit). We also examined outcome variables including the development of vitreous haemorrhage, retinal detachment, and clinically significant cataract requiring lens extraction surgery. Also recorded were the total duration of follow up and the time intervals between the initial baseline examination and each evaluated outcome.

\section{RESULTS}

There were 132 patients identified as eligible for the study. Complete follow up data were available on 107 patients $(81 \%)$, although we were able to ascertain outcome information on most of the remaining 25 individuals. Our analysis was conducted on the patients on whom we had complete data.

\section{Data presentation}

Table 1 summarises the patient demographics, baseline findings, Reese Ellsworth group and primary treatment methods employed for all the study patients. Table 2 cross tabulates the primary treatment in relation to their Reese Ellsworth grouping. Table 3 summarises the failures after primary treatment. This table cross tabulates the secondary treatment method with the primary conservative therapy in ascending order of Reese Ellsworth score and Table 4 presents the outcomes in patients requiring secondary treatments. Kaplan-Meier plots with $95 \%$ Greenwood confidence intervals of the estimated probability of new tumour development over time and of the estimated probability of primary treatment failure over time were constructed (Figs 1 and 2 ). In each case the "survival" time was taken as the time 


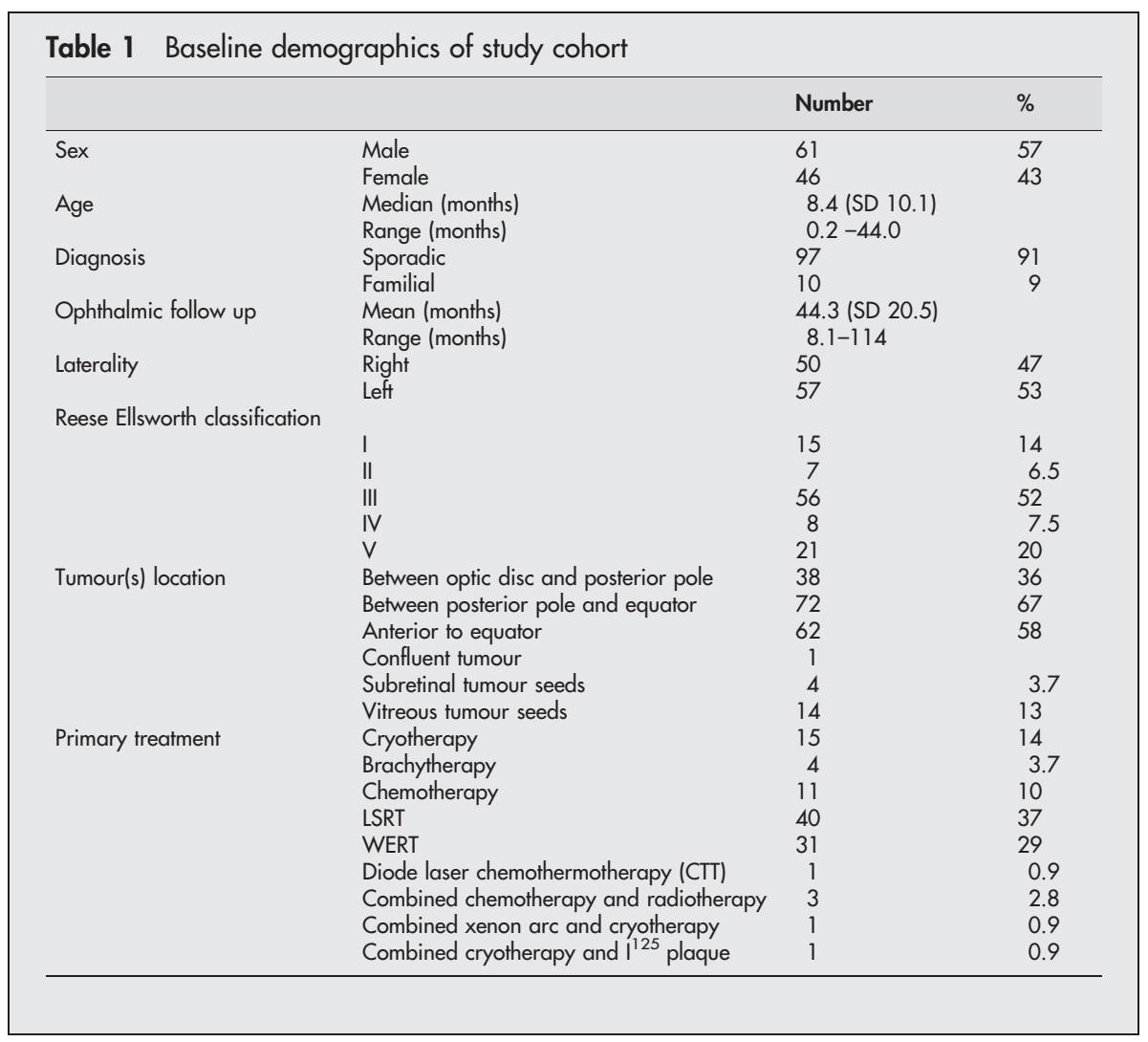

that the patient suffered the "survival event" (developed a new tumour, or primary treatment failed) or the follow up time if the patient did not suffer an event.

\section{Baseline findings}

The numbers of males and females and of right and left eyes were similar. The median age was 8.4 months (range $0.2-$ 44.0, SD 10.1 months). The median ophthalmic follow up was 44.3 months (range 8.1-114, SD 20.5 months). All patients remained on long term paediatric oncology follow up as described above and all but three of the study patients had a minimum of 3 years' follow up by the one or more members of the team. The majority of the study population was white $(87 \%)$. Ninety seven patients $(91 \%)$ had sporadic disease, 10 (9\%) had familial disease. No patient had raised intraocular pressure, iris neovascularisation, or anterior segment tumour in their study eye. Fifteen patients (14\%) had Reese Ellsworth group I, seven $(6.5 \%)$ patients had group II, 56 (52\%) had group III, eight $(7.5 \%)$ patients had group IV, and 21 patients $(20 \%)$ had group V disease in the remaining eye. The number of tumours ranged from one to six. One patient had confluent tumour, $38(36 \%)$ had tumours between the optic disc and posterior pole, $72(67 \%)$ had tumours between the posterior pole and the equator, and $62(58 \%)$ had tumours anterior to the equator. Four patients had subretinal seeds and 14 had vitreous tumour seeds. Snellen visual acuities were available in only 10 of the patients and ranged from hand movements to $6 / 6$ (Table 1 ).

\section{Primary treatment}

Fifteen patients (14\%) underwent cryotherapy, four $(3.7 \%)$ radioactive plaque brachytherapy, 11 (10\%) chemotherapy, and 40 (37\%) lens sparing external beam radiotherapy. Seven patients in the LSRT group also had adjuvant cryotherapy to anterior tumours in the first month after baseline examination. Thirty one patients $(29 \%)$ received whole eye external beam radiotherapy, three patients $(2.8 \%)$ received combined chemotherapy and external beam radiotherapy, and one patient $(0.9 \%)$ received CTT. Two underwent primary combined focal treatment. The 29 patients with Reese-Ellsworth group IV or V disease were treated with primary chemotherapy or external beam radiotherapy or a combination of both (Table 2).

Table 2 Primary conservative treatment method in relation to Reese Ellsworth group

\begin{tabular}{|c|c|c|c|c|c|c|c|c|c|}
\hline $\begin{array}{l}\text { Reese-Ellsworth } \\
\text { groups }\end{array}$ & $\begin{array}{l}\text { Cryotherapy } \\
(n=15)\end{array}$ & $\begin{array}{l}\text { Plaque } \\
(n=4)\end{array}$ & $\begin{array}{l}\text { Chemotherapy } \\
(n=11)\end{array}$ & $\begin{array}{l}\text { LSRT } \\
(n=40)\end{array}$ & $\begin{array}{l}\text { WERT } \\
(n=31)\end{array}$ & $\begin{array}{l}\text { Xenon+cryotherapy } \\
(n=1)\end{array}$ & $\begin{array}{l}C T \\
(n=1)\end{array}$ & $\begin{array}{l}\text { Plaque+cryotherapy } \\
(n=1)\end{array}$ & $\begin{array}{l}\text { Chemotherapy+WERT } \\
(\mathrm{n}=3)\end{array}$ \\
\hline I $(n=15)$ & 3 & 0 & 1 & 11 & 0 & 0 & 0 & 0 & 0 \\
\hline$\|(n=7)$ & 0 & 0 & 1 & 5 & 1 & 0 & 0 & 0 & 0 \\
\hline III $(n=56)$ & 12 & 4 & 5 & 21 & 11 & 1 & 0 & 1 & 1 \\
\hline IV $(n=8)$ & 0 & 0 & 0 & 3 & 5 & 0 & 0 & 0 & 0 \\
\hline$V(n=21)$ & 0 & 0 & 4 & 0 & 14 & 0 & 1 & 0 & 2 \\
\hline
\end{tabular}

LSRT = lens sparing radiotherapy, WERT $=$ whole eye radiotherapy, Plaque $=$ plaque brachytherapy, Xenon+cryotherapy $=$ combined indirect $x e n o n$ arc photocoagulation and cryotherapy, CTT = chemothermotherapy.

Initial treatment method for the retinoblastoma(s) in the study eye. 
Table 3 Secondary treatment method in relation to primary treatment and Reese Ellsworth score

\begin{tabular}{|c|c|c|c|c|c|c|c|c|}
\hline Patient & $\begin{array}{l}\text { Reese } \\
\text { Ellsworth } \\
\text { group }\end{array}$ & $\begin{array}{l}\text { Age at } \\
\text { baseline } \\
\text { (months) }\end{array}$ & $\begin{array}{l}\text { Follow up } \\
\text { (months) }\end{array}$ & Primary treatment & $\begin{array}{l}\text { Primary } \\
\text { treatment } \\
\text { failure }\end{array}$ & $\begin{array}{l}\text { New } \\
\text { tumours }\end{array}$ & $\begin{array}{l}\text { Type of secondary } \\
\text { treatment }\end{array}$ & $\begin{array}{l}\text { Outcome remission/ } \\
\text { enucleation }\end{array}$ \\
\hline 22 & 1 & 7 & 27 & Chemotherapy & Yes & Yes & Cryotherapy, LSRT & Remission \\
\hline 27 & 1 & 2 & 58 & LSRT & No & Yes & Cryotherapy, plaque & Remission \\
\hline 36 & 1 & 1 & 50 & LSRT & Yes & No & Plaque & Remission \\
\hline 40 & 1 & 1 & 67 & LSRT & No & Yes & Cryotherapy & Remission \\
\hline 4 & 2 & 3 & 18 & Chemotherapy & No & Yes & Cryotherapy & Remission \\
\hline 8 & 2 & 21 & 15 & WERT & Yes & No & Plaque & Remission \\
\hline 6 & 3 & 3 & 46 & Cryotherapy & No & Yes & Cryotherapy, LSRT & Remission \\
\hline 31 & 3 & 12 & 83 & Plaque + cryotherapy & Yes & No & Cryotherapy & Remission \\
\hline 42 & 3 & 3 & 26 & Chemotherapy & Yes & Yes & $\begin{array}{l}\text { Cryotherapy, plaque, } \\
\text { chemothermotherapy }\end{array}$ & Remission \\
\hline 44 & 3 & 3 & 74 & Cryotherapy & Yes & No & Cryotherapy & Remission \\
\hline 49 & 3 & 3 & 48 & LSRT & No & Yes & Cryotherapy & Remission \\
\hline 54 & 3 & 16 & 41 & LSRT & No & Yes & Cryotherapy & Remission \\
\hline 56 & 3 & 6 & 36 & WERT & Yes & No & $\begin{array}{l}\text { Xenon and cryotherapy, } \\
\text { plaque }\end{array}$ & Remission \\
\hline 60 & 3 & 16 & 32 & LSRT & No & Yes & Cryotherapy & Remission \\
\hline 66 & 3 & 33 & 75 & Cryotherapy & Yes & Yes & Plaque WERT & Remission \\
\hline 68 & 3 & 5 & 40 & LSRT & No & Yes & Cryotherapy & Remission \\
\hline 71 & 3 & 8 & 40 & LSRT & Yes & No & Cryotherapy, plaque & Remission \\
\hline 74 & 3 & 11 & 44 & Cryotherapy & Yes & No & Cryotherapy, plaque & Remission \\
\hline 81 & 3 & 6 & 41 & Xenon + cryotherapy & Yes & No & Cryotherapy, LSRT & Remission \\
\hline 89 & 3 & 4 & 69 & LSRT & No & Yes & Cryotherapy, plaque & Remission \\
\hline 92 & 3 & 6 & 48 & LSRT & Yes & Yes & Cryotherapy, plaque & Remission \\
\hline 96 & 3 & 12 & 48 & Cryotherapy & Yes & No & Cryotherapy, plaque & Remission \\
\hline 97 & 3 & 13 & 26 & Cryotherapy & Yes & No & Plaque, chemotherapy & Remission \\
\hline 100 & 3 & 4 & 22 & Cryotherapy & Yes & No & Cryotherapy, plaque & Remission \\
\hline 101 & 3 & 22 & 48 & LSRT & Yes & Yes & Plaque, iridium wire & Remission \\
\hline 102 & 3 & 5 & 50 & LSRT & No & Yes & Cryotherapy, plaque & Remission \\
\hline 103 & 3 & 6 & 73 & WERT & No & Yes & Cryotherapy & Remission \\
\hline 107 & 3 & 4 & 63 & WERT & No & Yes & Cryotherapy & Remission \\
\hline 45 & 4 & 7 & 41 & WERT & No & Yes & Cryotherapy, plaque & Remission \\
\hline 9 & 5 & 16 & 13 & Chemotherapy & Yes & No & Cryotherapy, plaque & Remission \\
\hline 12 & 5 & 6 days & 39 & Chemotherapy & No & Yes & Cryotherapy & Remission \\
\hline 16 & 5 & 7 & 72 & WERT & Yes & No & Cryotherapy & Remission \\
\hline 23 & 5 & 1 & 73 & WERT & Yes & Yes & Chemotherapy, plaque & Enucleation \\
\hline 53 & 5 & 44 & 34 & WERT & Yes & No & Cryotherapy, plaque & Enucleation \\
\hline 57 & 5 & 34 & 86 & Chemotherapy + WERT & Yes & No & $\begin{array}{l}\text { Cryotherapy, plaque, } \\
\text { chemotherapy }\end{array}$ & Remission \\
\hline 72 & 5 & 18 & 24 & Chemotherapy & Yes & Yes & Cryotherapy, WERT & Remission \\
\hline 79 & 5 & 29 & 35 & WERT & No & Yes & Cryotherapy & Remission \\
\hline 86 & 5 & 8 & 60 & WERT & Yes & Yes & Cryotherapy, plaque & Enucleation \\
\hline 93 & 5 & 35 & 70 & WERT & Yes & No & None & Enucleation \\
\hline 99 & 5 & 12 & 58 & WERT & Yes & No & $\begin{array}{l}\text { Chemotherapy, iridium } \\
\text { wire, plaque, intravitreal } \\
\text { thiotepa }\end{array}$ & Enucleation \\
\hline
\end{tabular}

LSRT = lens sparing radiotherapy, WERT $=$ whole eye radiotherapy, plaque $=$ radioactive plaque brachytherapy, iridium wire $=$ iridium-192 plaque brachytherapy for vitreous base recurrence, xenon+ cryotherapy = combined indirect xenon arc photocaogulation and cryotherapy.

Primary treatment failures and new tumours

Forty patients $(37 \%)$ had secondary treatments for primary treatment failures and/or new tumours. All these patients had secondary focal treatments and in addition 12 patients
(11\%) received secondary non-focal treatments (chemotherapy and/or radiotherapy) to control their tumours (Table 3). There were 25 primary treatment failures $(23 \%)$. All patients who failed primary treatment did so within 31.8 months of

Table 4 Outcomes of secondary conservative treatment

\begin{tabular}{|c|c|c|c|c|c|c|c|c|c|}
\hline $\begin{array}{l}\text { Outcomes of treatments } \\
\text { evaluated in this study }\end{array}$ & $\begin{array}{l}\text { Cryo- } \\
\text { therapy } \\
(n=15)\end{array}$ & $\begin{array}{l}\text { Plaque } \\
(n=4)\end{array}$ & $\begin{array}{l}\text { Chemo- } \\
\text { therapy } \\
(\mathrm{n}=11)\end{array}$ & $\begin{array}{l}\text { LSRT } \\
(\mathrm{n}=40)\end{array}$ & $\begin{array}{l}\text { WERT } \\
(\mathrm{n}=31)\end{array}$ & $\begin{array}{l}\text { Xenon+ } \\
\text { cryotherapy } \\
(\mathrm{n}=1)\end{array}$ & $\begin{array}{l}\mathrm{CTT} \\
(\mathrm{n}=1)\end{array}$ & $\begin{array}{l}\text { Plaque +cryotherapy } \\
(\mathrm{n}=1)\end{array}$ & $\begin{array}{l}\text { Chemotherapy+WERT } \\
(\mathrm{n}=3)\end{array}$ \\
\hline New tumours $(n=24)$ & 3 & 0 & 5 & 10 & 6 & 0 & 0 & 0 & 0 \\
\hline $\begin{array}{l}\text { Primary treatment failures } \\
(n=25)\end{array}$ & 6 & 0 & 4 & 4 & 8 & 1 & 0 & 1 & 1 \\
\hline Enucleation $(n=5)$ & 0 & 0 & 0 & 0 & 5 & 0 & 0 & 0 & 0 \\
\hline Death $n=8$ ) & 1 & 0 & 1 & 1 & 5 & 0 & 0 & 0 & 0 \\
\hline Cataract surgery $(n=24)$ & 0 & 0 & 0 & 1 & 20 & 0 & 0 & 0 & 3 \\
\hline $\begin{array}{l}\text { Vitreous haemorrhage } \\
(\mathrm{n}=4)\end{array}$ & 0 & 0 & 0 & 1 & 3 & 0 & 0 & 0 & 0 \\
\hline Retinal detachment $(n=4)$ & 0 & 0 & 1 & 1 & 1 & 0 & 0 & 0 & 1 \\
\hline
\end{tabular}

LSRT = lens sparing radiotherapy, WERT = whole eye radiotherapy, Plaque = plaque brachytherapy, Xenon+cryotherapy $=$ combined indirect xenon arc photocoagulation and cryotherapy, $\mathrm{CT}=$ chemothermotherapy. Initial treatment method for the retinoblastoma(s) in the study eye. 


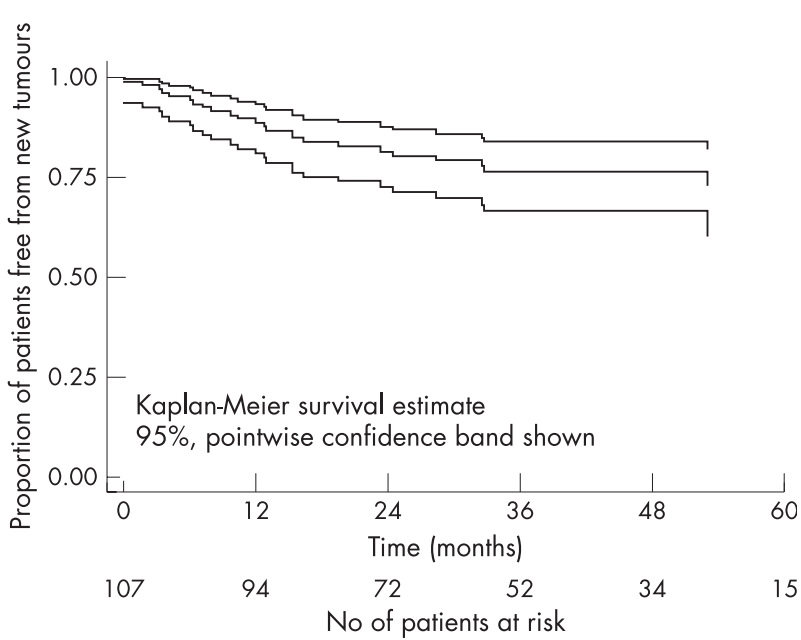

Figure 1 Kaplan-Meier estimate of cumulative new tumour free survival in 107 children with bilateral retinoblastoma treated by primary enucleation of the worse eye and primary conservative treatment of the better eye.

the baseline examination. Twenty four patients (23\%) developed new tumours. All patients who developed new tumours did so within 53.0 months of the baseline examination (Table 4).

\section{Enucleation and death}

Five patients $(4.6 \%)$ each had their only eye enucleated after failure of globe conserving treatment. All these patients had Reese Ellsworth group V disease. Enucleation was advised for one further patient after failure of conservative treatment but the operation was refused and this child was subsequently lost to follow up. The remaining patients were in remission at the time of their last follow up/death. A total of eight patients (7.5\%) died from retinoblastoma related causes. Two patients died from extraocular spread of retinoblastoma. Five patients $(4.5 \%)$ died from ectopic intracranial retinoblastoma. One patient died from acute myeloid leukaemia after undergoing chemotherapy as the primary treatment.

\section{Anatomical outcome}

Twenty four patients (22\%) developed clinically significant cataract for which lens extraction surgery was indicated. Twenty of these patients had undergone WERT and three had undergone combined chemotherapy and WERT, either as primary or secondary treatments. One patient had primary LSRT and a secondary cobalt plaque brachytherapy. Four patients $(3.7 \%)$ with eyes in Reese Ellsworth groups IV and V developed vitreous haemorrhage during the course of their treatment. Three of these patients were in Reese Ellsworth group $\mathrm{V}$ at diagnosis and subsequently lost their only eye (patients 23, 53, 86). The fourth patient with a Reese Ellsworth group 3 eye underwent primary LSRT with adjuvant cryotherapy and then developed vitreous haemorrhage despite adequate tumour control. Four $(3.7 \%)$ patients developed retinal detachment. All the retinal detachments were stable and did not require vitreoretinal surgery.

\section{DISCUSSION}

The main objective of retinoblastoma treatment is to preserve life, but with the 3 year survival rate of around $90 \%,{ }^{12}$ every attempt is also made to preserve the patient's eye(s) and some degree of useful vision. In recent years the management approach in London has been to assess each eye on its individual merits, and enucleation is no longer performed in a bilateral case solely because an eye is the worse affected of

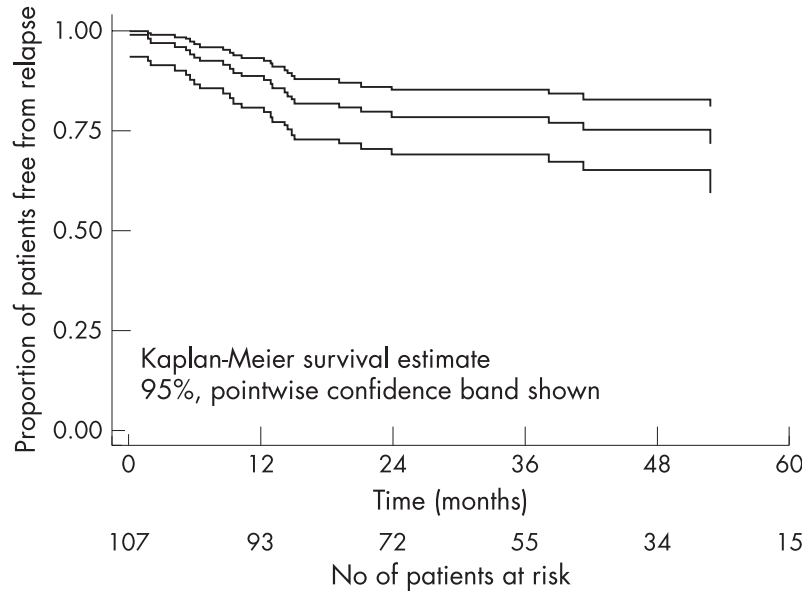

Figure 2 Kaplan-Meier estimate of cumulative primary treatment failure free survival of 107 children with bilateral retinoblastoma treated by primary enucleation of the worse eye and primary conservative treatment of the better eye.

the two. Routine enucleation of the worse eye and conservative therapy of the better was abandoned because of a significant relapse rate in the so called "better eye." This policy was endorsed by the discovery that, when both eyes received conservative treatment, what had been thought to be the worse eye was sometimes the only one retained. Bilateral retinoblastoma occurs in 1:60 000 live births, ${ }^{1}$ constituting approximately $35 \%$ of all cases. As we found in our study, almost all cases involving both eyes present within the first 3 years of life. With modern treatment, retinoblastoma has an excellent 3 year survival rate. Children with bilateral retinoblastoma, however, have been shown in later life to have a 300-fold increased risk of developing bone and soft tissue sarcoma, a 100-fold increased risk of malignant melanoma, and a 24 -fold increased risk for brain cancer. ${ }^{4}$ Patients who had undergone external beam radiotherapy were at threefold increased risk compared to those not treated by radiotherapy as well as having a $90 \%$ risk of orbital deformities. ${ }^{11}$ The mortality risk from chemotherapy has not yet been quantified.

Sanders ${ }^{1}$ examined the retinoblastoma demographics in the United Kingdom. He noted a general trend towards conservative treatment with $73 \%$ of bilateral retinoblastoma patients retaining one eye in the 1960s compared to $83 \%$ in the 1970s. In Migdal's ${ }^{3}$ series of bilateral retinoblastoma from our service, $65 \%$ had one and $22 \%$ had both eyes enucleated but $50 \%$ of his cohort retained a visual acuity of $6 / 12$ or better. The bilateral RB patients in the present study had lost one eye at the beginning of their treatment; therefore all treatments were focused from the start on the goal of retaining a useful eye. The questions we had to ask ourselves were how far should the clinician attempt conservative treatment in this genetically susceptible group, what impact did this have on our young patients' quality of life, and how much did the eyes we salvaged see? Moreover, did we jeopardise the patients' survival in our aggressive conservative treatment of their remaining eye? The globe preservation rate of $95 \%$ that we achieved compared well with historical controls. $^{7-9}$ If we consider the individual primary treatments supplemented, where necessary, by secondary therapy, all therapeutic modalities except for WERT showed a 100\% salvage rate. Even for WERT the globe preservation rate was $84 \%$. Given that LSRT was available for most of the study period and that patients selected for WERT would be biased for more advanced disease, this compares well with the previous published value $(80 \%)$ reported from our centre. ${ }^{7}$ 
Considering the results for group $\mathrm{V}$ eyes with aggressive conservative treatment, our eye preservation rate was $76 \%$ $(16 / 21)$ in this study compared with own previous published value of $66 \%,{ }^{9}$ and only $47 \%$ in a more recent study using chemoreduction and focal therapy. ${ }^{12}$ It was also reassuring to note that our 3 year survival rate of 95\% (99/104) was comparable with previous published results. Most of the deaths resulted from ectopic intracranial retinoblastoma, the incidence of which was $4.5 \%$ in the current cohort compared with $2.3 \%{ }^{13}$ in our published study addressing specifically ectopic intracranial retinoblastoma. We did, however, record two deaths caused by disseminated metastatic disease after the patients had undergone multiple globe saving procedures. In one patient delayed enucleation may have been contributory though we do not know at what earlier stage removal of the eye might have produces a happier outcome. The second patient is thought to have died from metastatic spread from the already enucleated first eye. Although we were able to control the disease in the remaining eye, the enucleated globe had adverse histology but was managed before our now established practice of giving adjuvant chemotherapy in such cases. ${ }^{14}$ It was also a cause for concern that, given the current widespread use of chemotherapy as the first line treatment for all tumours that were unsuitable for focal treatment, one of our patients died from acute myeloid leukaemia possibly induced by etoposide. ${ }^{15}$ We found, as did Bechrakis ${ }^{16}$ and Gallie, ${ }^{17}$ that chemotherapy alone was less powerful than external beam radiation to control tumour growth. Often, despite good initial response, focal reactivation occurred either during or, more often, after cessation of chemotherapy and this necessitated secondary treatment. Our results of $36 \%$ primary treatment failures and $45 \%$ new tumours in the chemotherapy group served to highlight the frequent need for additional focal therapy in this group, and recent work from Shields et al ${ }^{18}$ and our own unit $^{19}$ have identified risk factors for relapse after primary chemotherapy. Shields et $a l^{12}$ reported a 5 year globe preservation rates of $85 \%$ in groups I-IV eyes and only $47 \%$ in group $\mathrm{V}$ eyes with chemotherapy in conjunction with radiation or focal treatments,. These findings supported the findings of Bechrakis and coworkers ${ }^{16}$ that histologically active tumour was still present after chemotherapy.

A significant number of our patients underwent multiple treatments resulting in cataract, serous and tractional retinal detachment, ischaemic maculopathy, optic neuropathy, and vitreous haemorrhage. All the treatments used could induce morbidity. Cryotherapy frequently caused significant ocular discomfort, conjunctival chemosis, and anterior segment inflammation. Used to excess it can occasionally produce serous retinal detachment leading to pigment fallout at the macula when employed on the temporal side. Diode laser chemothermotherapy was employed mostly for posterior tumours where parafoveal scars and macular traction can affect central vision. Plaque brachytherapy used a the sole treatment rarely produces significant side effects but employed as a secondary, salvage therapy can have quite a severe adverse influence on vision, a finding also supported by Shields et al..$^{20}$ We found that previous chemotherapy and especially previous external beam radiotherapy or worse still, both, led to potentiation of the radiation effect and, in turn, to localised ischaemia. This effect was most noticeable as localised vitreous haemorrhage when peripheral lesions were treated and rarely had any major effect on central vision except, perhaps, for tumours located superiorly. In the rare instances when we were obliged to use plaque salvage for posterior retinoblastomas, radiation maculopathy and ischaemic optic neuropathy were important and visually destructive sequelae of the radio-potentiation effect. In London, we have always tried to avoid using plaques behind the equator but we found this policy particularly important after previous chemotherapy or radiotherapy.

In our salvage as in our primary treatment strategies we have always taken account of the long term risks, particularly in this genetically susceptible population with bilateral disease. Although chemotherapy was believed to lower the incidence of second tumours, the risk of leukaemia ${ }^{15}$ induced by ectoposide was very real as shown by one death from acute myeloid leukemia in our cohort. We learned that, when considering the use of multiple chemotherapeutic and radioactive interventions, it is extremely important to consider not only the visual potential of the eye but also the risk of persistent drug and radiation resistant tumour leading to metastatic disease.

With the current shift of therapeutic strategy towards chemotherapy and multiple salvage treatments it has become more than ever essential that children be managed in a tertiary referral centre equipped and experienced in the full repertoire of retinoblastoma treatments. The adoption of chemotherapy in preference to external beam radiotherapy as the primary treatment method has increased rather than reduced the need for focal treatments in our centre. We were encouraged to find that we have salvaged the great majority of these only eyes with no apparent detrimental effect on the patients' survival. It will be some time, however, before we know exactly how well these children will see compared with the generation treated by older methods, albeit with their own morbidities. Only then will we be fully able to judge expertly when the local and systemic adverse effects of multiple therapies may outweigh their advantages with regard to long term quality of life.

\section{Authors' affiliations}

V Lee, J L Hungerford, F Ahmed, Ocular Oncology Service, St Bartholomew's and Moorfields Eye Hospital London, UK

C Bunce, Medical Statistics, Research and Development, Moorfields Eye Hospital, London, UK

J E Kingston, Department of Paediatric Oncology, St Bartholomew's Hospital, London, UK

P N Plowman, Department of Radiotherapy, St Bartholomew's Hospital, London, UK

The authors have no financial or proprietary interest in any of the materials used in this study.

\section{REFERENCES}

1 Sanders BM, Draper GJ, Kingston JE. Retinoblastoma in Great Britain 1969-1980: incidence, treatment and survival. Br J Ophthalmol 1988:72:576-83

2 Shields JA, Shields CL. Current management of retinoblastoma. Mayo Clin Roc 1994;69:550-6.

3 Migdal C. Bilateral retinoblastoma: the prognosis for vision. Br J Ophthalmol 1983;67:592-5.

4 Eng C, Li FP, Abramson D, et al. Mortality from second tumours among longterm survivors of retinoblastoma. J Natl Cancer Inst 1993:85:1121-8.

5 Madreperla SA, Hungerford JL, Doughty D, et al. Treatment of retinoblastoma vitreous base seeding. Ophthalmology 1998;105:120-4.

6 Murphree AL, Villablanca JG, Deegan III WF, et al. Chemotherapy plus local treatment in the management of intraocular retinoblastoma. Arch Ophthalmol 1996; 114:1348-56.

7 Hungerford JL, Toma NMG, Plowman PN, et al. External beam radiotherapy for retinoblastoma: I Whole eye technique. Br J Ophthalmol 1995;79:109-11.

8 Toma NMG, Hungerford JL, Plowman PN, et al. External beam radiotherapy for retinoblastoma: II Lens sparing technique. Br J Ophthalmol 1995;79: 112-17

9 Kingston JE, Hungerford JL, Madreperla SA, et al. Results of combined chemotherapy and radiotherapy for advanced intraocular retinoblastoma. Arch Ophthalmol 1996:114:1339-43.

10 Ellsworth RM. Retinoblastoma. Mod Probl Ophthal 1977;18:94-100.

11 Imhof SM, Hofman P, Tan KE. Quantification of lacrimal function after D shaped field irradiaton for retinoblastoma. Br J Ophthalmol 1993;77:482-4.

12 Shields CL, Honavar SG, Meadows A, et al. Chemoreduction plus focal therapy for retinoblastoma: factors predictive of need for treatment with external beam radiotherapy or enucleation. Am J Ophthalmol 2002; 133:657-64.

13 Kingston JE, Plowman PN, Hungerford JL. Ectopic intracranial retinoblastoma in childhood. Br J Ophthalmol 1985;69:742-8. 
14 Olver JM, McCartney ACE, Kingston J et al. Histological indicators of the prognosis for survival following enucleation for retinoblastoma. In: Bornfeld N, Gragoudas ES, Höpping W, eds. Tumors of the eye. Proceedings of the International Symposiums in 1987 and 1989. Amsterdam: Kugler, 1991:59-67.

15 Winick NJ, Mckenna RW, Shunter JJ, et al. Secondary acute myeloid leukemia in children with acute lymphoblastic leukemia treated with ectoposide. Clin Oncol 1993:11:209-17.

16 Bechrakis NE, Bornfeld N, Schueler A, et al. Clinicopathologic features of retinoblastoma after primary chemoreduction. Arch Ophthalmol 1998; 1 16:887-93.
17 Gallie BL, Budning A, Deboer G et al. Chemotherapy with focal therapy can cure intraocular retinoblastoma without radiotherapy. Arch Ophthalmol 1996; 114:1321-8.

18 Shields CL, Honavar SG, Shields JA, et al. Factors predictive of recurrence of retinal tumors, vitreous seeds, and subretinal seeds following chemoreduction for retinoblastoma. Arch Ophthalmol 2002;120:460-4.

19 Gombos DS, Kelly A, Coen PG, et al. Retinoblastoma treated with primary chemotherapy: the significance of tumour size, location and age. Br J Ophthalmol 2002;86:80-3.

20 Shields CL, Shields JA, Cater J, et al. Plaque radiotherapy for retinoblastoma: long-term tumor control and treatment complications in 208 tumors. Ophthalmology 2001;108:21 16-21.

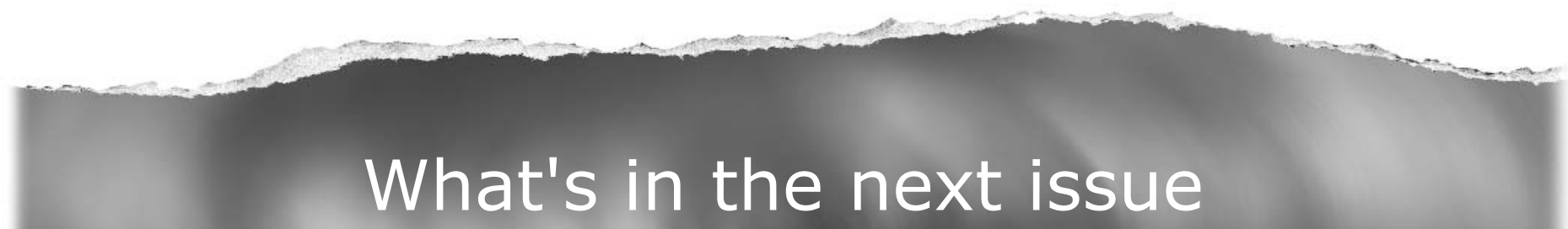

\section{Future content}

See which articles have just been accepted for publication and preview the table of contents for the next issue a month before it is published

www.bjophthalmol.com 